\title{
TRUEX Radiolysis Testing Using the INL Radiolysis Test Loop: FY-2012 Status Report
}

Dean R. Peterman

Lonnie G. Olson

Richard D. Tillotson

Rocklan G. McDowell

Jack D. Law

September 2012

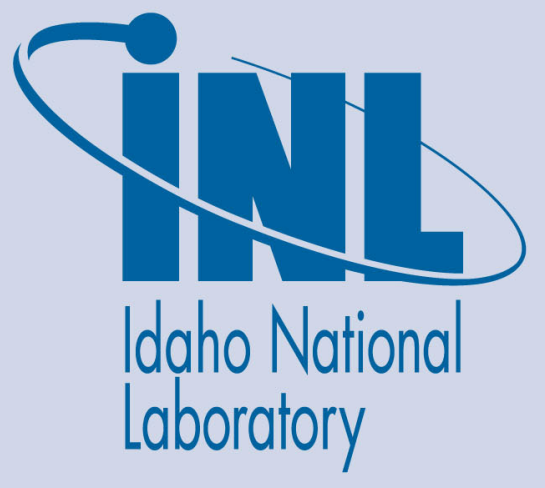

The INL is a U.S. Department of Energy National Laboratory operated by Battelle Energy Alliance 
INL/EXT-12-27285

FCRD-SWF-2012-000303

\title{
TRUEX Radiolysis Testing Using the INL Radiolysis Test Loop: FY-2012 Status Report
}

\author{
Dean R. Peterman \\ Lonnie G. Olson \\ Richard D. Tillotson \\ Rocklan G. McDowell \\ Jack D. Law
}

September 2012

\author{
Idaho National Laboratory \\ Fuel Cycle Research \& Development \\ Idaho Falls, Idaho 83415
}

http://www.inl.gov

Prepared for the

U.S. Department of Energy

Office of Nuclear Energy

Under DOE Idaho Operations Office

Contract DE-AC07-05ID14517 

DISCLAIMER

This information was prepared as an account of work sponsored by an agency of the U.S. Government. Neither the U.S. Government nor any agency thereof, nor any of their employees, makes any warranty, expressed or implied, or assumes any legal liability or responsibility for the accuracy, completeness, or usefulness, of any information, apparatus, product, or process disclosed, or represents that its use would not infringe privately owned rights. References herein to any specific commercial product, process, or service by trade name, trade mark, manufacturer, or otherwise, does not necessarily constitute or imply its endorsement, recommendation, or favoring by the U.S. Government or any agency necessarily state or reflect those of the U.S. Government or any agency 


\section{SUMMARY}

This report presents a summary of the work performed to meet the FCRD level 3 milestone M3FT12IN0302032, "TRUEX strip/TALSPEAK feed degradation mechanism." The INL radiolysis test loop has been used to evaluate the effects of radiolytic degradation upon the efficacy of the strip section of the TRUEX flowsheet for the recovery of trivalent actinides and lanthanides from acidic solution. The nominal composition of the TRUEX solvent used in this study is $0.2 \mathrm{M} \mathrm{CMPO}$ and 1.4 M TBP dissolved in n-dodecane and the nominal composition of the TRUEX strip solution is $1.5 \mathrm{M}$ lactic acid and $0.050 \mathrm{M}$ diethylenetriaminepentaacetic acid. Gamma irradiation of a mixture of TRUEX process solvent and stripping solution in the test loop does not adversely impact flowsheet performance as measured by stripping americium ratios. The observed increase in americium stripping distribution ratios with increasing absorbed dose indicates the radiolytic production of organic soluble degradation compounds. While the observed increases in the americium stripping distributions with increasing absorbed dose are statistically significant, the increase from $\mathrm{D}_{\mathrm{Am}}=<0.001$ at $0 \mathrm{kGy}$ absorbed dose to $\mathrm{D}_{\mathrm{Am}}=0.015$ at 1300 kGy absorbed dose is not an insurmountable difficulty. A more troubling observation is the significant decrease in the solvent dispersion number as the strip section of the TRUEX flowsheet is subjected to gamma radiolysis. The dispersion number, $\mathrm{N}_{\mathrm{Di}}$, determined for un-irradiated TRUEX solvent and strip solution is $\mathrm{N}_{\mathrm{Di}}=1.05 \times 10^{-3}$, which is an acceptable value for typical solvent extraction equipment. However, the dispersion number for the irradiated TRUEX solvent and strip solution is $3.94 \times 10^{-4}$, which is a poor value for typical solvent extraction equipment. Dispersion number determinations for mixture of irradiated and un-irradiated solutions suggest that both the aqueous and organic phases play a role in the decrease of the solvent dispersion number. 


\section{CONTENTS}

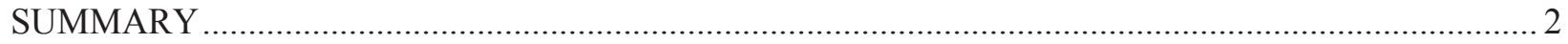

ACRONYMS

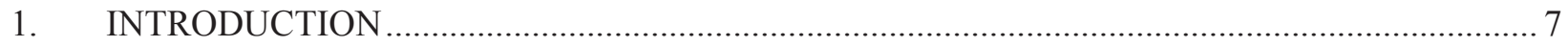

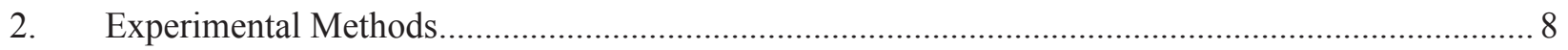

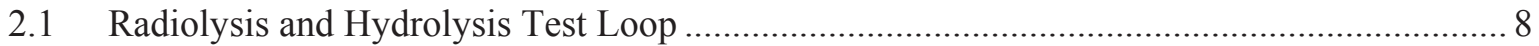

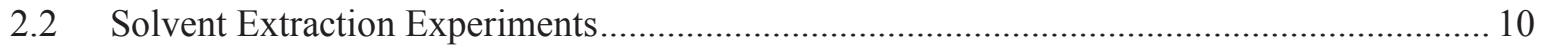

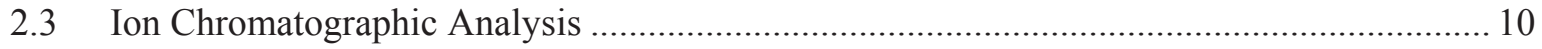

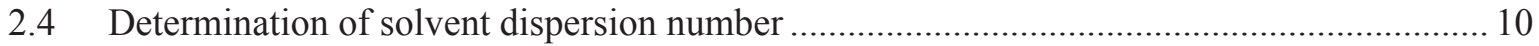

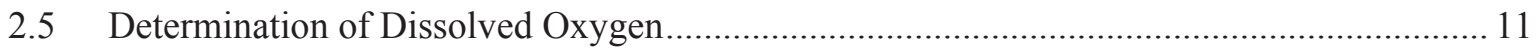

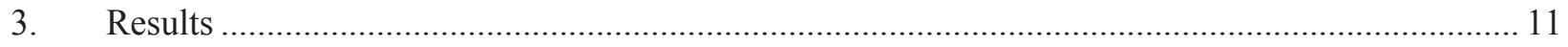

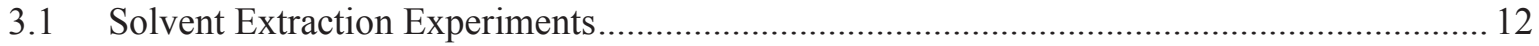

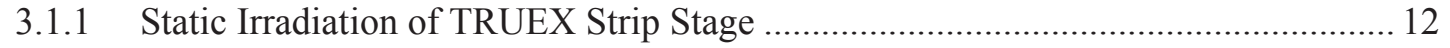

3.1.2 Test Loop Irradiation of TRUEX Strip Stage ......................................................... 12

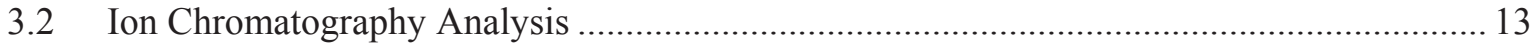

3.2.1 Static Irradiation of TRUEX Strip Stage ….................................................... 13

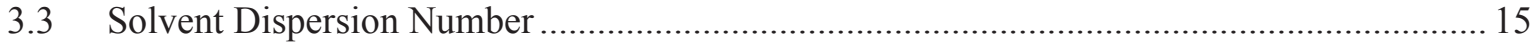

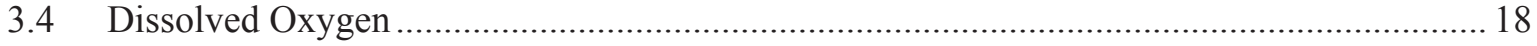

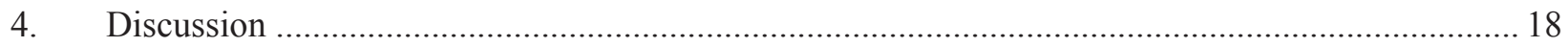

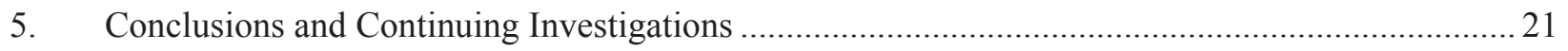

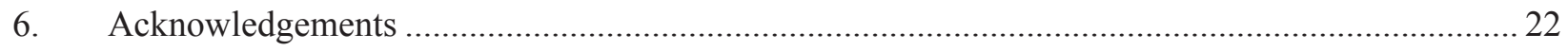

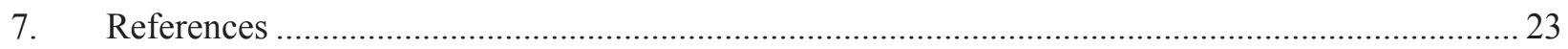




\section{FIGURES}

Figure 1. MDS Nordion GammaCell 220 gamma irradiator. ......................................................... 8

Figure 2. Schematic diagram of the INL Radiolysis and Hydrolysis Test Loop..................................... 9

Figure 3. Am(III) distribution ratios as a function of absorbed dose for static irradiation of the TRUEX aqueous strip only (open circles) and static irradiation of TRUEX strip phase in contact with TRUEX sovlent (open squares).

Figure 4. Am(III) distribution ratios as a function of absorbed dose for test loop irradiation of the TRUEX aqueous strip in contact with TRUEX solvent. Determination with irradiated aqueous and organic phases (open circles) and irradiated aqueous and fresh organic (open squares).....

Figure 5. Plot of peak area response versus lactic acid concentration for the ion chromatographic determination of lactic acid in solution.

Figure 6. Plot of the concentration of lactic acid determined by ion chromatography as a function of absorbed dose for the static irradiation of TRUEX strip phase only.

Figure 7. Phase separation of irradiated TRUEX solvent and TRUEX strip solution after $240 \mathrm{kGy}$ absorbed dose. Complete phase separation requires greater than four minutes.

Figure 8. Phase separation of irradiated TRUEX solvent and TRUEX strip solution after $400 \mathrm{kGy}$ absorbed dose. Complete phase separation requires greater than four minutes.

Figure 9. Phase separation of irradiated TRUEX solvent and TRUEX strip solution after 1040 $\mathrm{kGy}$ absorbed dose. Complete phase separation requires greater than eight minutes. .16

Figure 10. Phase separation of irradiated TRUEX solvent and TRUEX strip solution after 1270 $\mathrm{kGy}$ absorbed dose. Complete phase separation requires greater than six minutes. 
TRUEX Radiolysis Testing Using the INL Radiolysis Test Loop: FY-2012 Status Report

\section{TABLES}

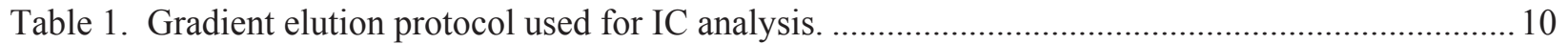

Table 2. Break times, temperatures, and values of $\mathrm{N}_{\mathrm{Di}}$ for the investigated solvent systems.................. 17 


\section{ACRONYMS}

$\begin{array}{ll}\text { AMUSE } & \text { Argonne Model for Universal Solvent Extraction } \\ \text { CINC } & \text { Costner Industries Nevada Corporation } \\ \text { CMPO } & \text { Octyl(phenyl)-N, N-diisobutylcarbamoylmethyl phosphine oxide } \\ \text { DO } & \text { Dissolved oxygen } \\ \text { DTPA } & \text { Diethylenetriaminepentaacetic acid } \\ \text { ESI-MS } & \text { Electrospray ionization mass spectrometry } \\ \text { IC } & \text { Ion chromatography with conductivity detection } \\ \text { INL } & \text { Idaho National Laboratory } \\ \text { LET } & \text { Linear energy transfer } \\ \text { TRUE } & \text { Tri-butylphosphate } \\ \text { TALSPEAK } & \begin{array}{l}\text { Trivalent Actinide Lanthanide Separation by Phosphorous reagent Extraction from } \\ \text { Aqueous Komplexes }\end{array} \\ \text { ORP } & \text { Oxidation Reduction Probe } \\ & \text { Plutonium Uranium Reduction Extraction } \\ \text { TRE } & \end{array}$




\section{SEPARATIONS CAMPAIGN}

\section{SUMMARY OF TRUEX RADIOLYSIS TESTING USING THE INL RADIOLYSIS TEST LOOP}

\section{INTRODUCTION}

The radiolysis/hydrolysis test loop, located at the Idaho National Laboratory (INL), was utilized to study the impacts of radiolytic and hydrolytic degradation products on the performance of the TRansUranic EXtraction (TRUEX) process. The TBP/alkane diluent system has received extensive attention in the scientific literature for at least the last forty years. The radiation chemistry of the TBP was recently reviewed by Mincher and co-authors. [1] Further, Mincher et al. have also recently reviewed the radiation chemistry of organophosphorus extractants such as octylphenyl-N,Ndiisobutylcarbamoylmethyl phosphine oxide (CMPO), one of the components of the TRUEX process solvent. [2]

The successful deployment of any solvent extraction ligand proposed for use in fuel cycle separations will depend upon the stability of that ligand in an acidic, radioactive environment. Irradiation of the ligand occurs due to the decay energy of actinides and fission products in the dissolved nuclear fuel solution. The radiation types are predominantly low linear energy transfer (LET) beta/gamma radiation from fission product decay, and high LET alpha radiation from actinide decay. The major reactive species formed $[3,4]$ by radiolysis of water, alkane diluent, and nitric acid are shown in Equations $1-3$, respectively.

$$
\begin{aligned}
& \mathrm{H}_{2} \mathrm{O}-\mathrm{W} \rightarrow{ }^{\circ} \mathrm{OH}+\mathrm{e}^{-}+\mathrm{H}^{\cdot}+\mathrm{H}_{2} \mathrm{O}_{2}+\mathrm{H}_{3} \mathrm{O}^{+}+\mathrm{H}_{2} \\
& \mathrm{CH}_{3}\left(\mathrm{CH}_{2}\right)_{\mathrm{n}} \mathrm{CH}_{3}-\mathrm{W} \rightarrow \mathrm{e}^{-}{ }_{\text {sol }}+\mathrm{CH}_{3}\left(\mathrm{CH}_{2}\right)_{\mathrm{n}} \mathrm{CH}_{3}{ }^{++}+\mathrm{CH}_{3}\left(\mathrm{CH}_{2}\right)_{n} \mathrm{CH}_{2} \cdot+{ }^{\cdot} \mathrm{CH}_{3}+\mathrm{H}^{\cdot}+\mathrm{H}_{2} \\
& \mathrm{HNO}_{3}-\mathrm{M} \rightarrow \mathrm{NO}_{2}+{ }^{-} \mathrm{NO}_{3}+, \mathrm{HNO}_{2}
\end{aligned}
$$

Equations $1-3$ show that radiolysis of aqueous and organic phases generates a range of oxidizing $\left({ }^{\circ} \mathrm{OH},{ }^{\circ} \mathrm{NO}_{3},{ }^{\circ} \mathrm{NO}_{2}\right)$ radicals, reducing $\left(\mathrm{H}^{\circ}\right)$ radicals, the reducing aqueous electron $\left(\mathrm{e}^{-}\right.$aq $)$, and reactive molecular species $\left(\mathrm{H}_{2} \mathrm{O}_{2}, \mathrm{HNO}_{2}, \mathrm{H}_{2}\right)$.

Due to relatively low ligand concentrations employed most decay energy is absorbed by the diluent and ligand radiolysis is expected to occur by indirect, rather than direct mechanisms. [5] For example, the proposed TRUEX solvent contains $0.2 \mathrm{M} \mathrm{CMPO}$ as the ligand, while the tributylphosphate (TBP) modifier and dodecane diluent concentrations are about $1.4 \mathrm{M}$ and $3 \mathrm{M}$, respectively. Consequently, most ligand damage will be due to reaction with reactive species created by energy deposition in the balance of the organic phase, or in the acidic aqueous phase in contact with that organic phase. Therefore, realistic examination of the impacts of radiolytic degradation upon the efficacy of solvent extraction processes 
used in an advanced nuclear fuel cycle, necessitates studying the radiolysis of mixed aqueous and organic systems.

\section{Experimental Methods}

\subsection{Radiolysis and Hydrolysis Test Loop}

The design, construction, and installation of the solvent radiolysis and hydrolysis test loop have been described previously. [6] The irradiation source (see Figure 1) is a MDS Nordion GammaCell 220 Excel self-contained ${ }^{60} \mathrm{Co}$ gamma irradiator. The center-line gamma dose rate in the sample chamber is approximately $6.4 \mathrm{kGy} / \mathrm{hr}$. The solvent irradiation loop is based upon a coil of borosilicate glass tubing ( 0.375 " OD, 0.202 " ID) which is placed in the gamma irradiator sample chamber. The current effective gamma dose rate in the test loop is $3.3 \mathrm{kGy} / \mathrm{hr}$. During the solvent irradiation, the aqueous and organic phases are mixed using a centrifugal contactor (CINC V-02, USA) with the rotor replaced by a

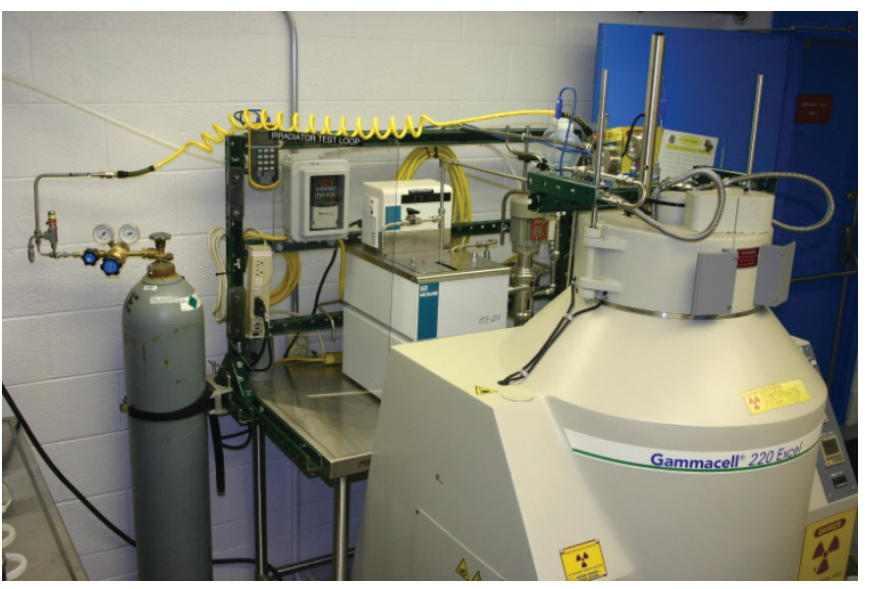

Figure 1. MDS Nordion GammaCell 220 gamma irradiator. four vane mixing paddle. The interior of the centrifugal contactor housing may be purged with inert gas, if necessary. The organic and aqueous phases used are metered into the mixing region of the contactor at the desired organic to aqueous phase ratio $(\mathrm{O} / \mathrm{A})$. The mixed phases are pumped through the irradiator test loop by a magnetic drive gear pump. The mixed phases flow through the glass coil in the irradiator sample chamber, through an external coil in a water bath, and return to the inlet of the centrifugal contactor where the phases are mixed and circulated back through the loop. In-line tube mixers (TAH Industries, Inc.) are used to provide additional phase mixing in the test loop. The in-line tube mixers are placed between the outlet of the gear drive pump and the inlet of the irradiation loop and between the outlet of the irradiation loop and the inlet to the external temperature control coil. The flowrate of the dispersion is in the range of $1.5 \mathrm{~L} / \mathrm{min}$ in order to maintain turbulent flow and keep the phases dispersed. The radiolysis/hydrolysis test loop is equipped with pressure gauges and thermocouples before and after the gamma irradiator. Two flow sight glasses are used to monitor the extent of mixing in the test loop. The two phases continue to circulate until the desired dose is obtained.

The temperature inside the sample chamber is $\sim 38{ }^{\circ} \mathrm{C}$ due to the decay heat of the ${ }^{60} \mathrm{Co}$ source. Lower temperature irradiations are possible by using the off-gas of a liquid nitrogen dewar and a control valve interfaced to a temperature controller to maintain a temperature below $38{ }^{\circ} \mathrm{C}$ in the sample chamber. The lower limit for the operating temperature has not been determined, but irradiations at $10{ }^{\circ} \mathrm{C}$ are possible. A temperature-controlled water bath (external to the sample chamber) is used to maintain the desired temperature of the test solutions within the test loop. The sampling port permits samples to be withdrawn from the test loop in order to monitor the conditions during an irradiation. To facilitate hydrolysis of the solvent in the test loop, this setup will allow the solution to be maintained at an elevated temperature throughout testing if desired. A flow cell and dissolved oxygen sensor was added in FY2012 in order to monitor the amount of oxygen present in the test loop solution during gamma radiolysis or without gamma radiolysis. A schematic view of the test loop is shown in Figure 2. 


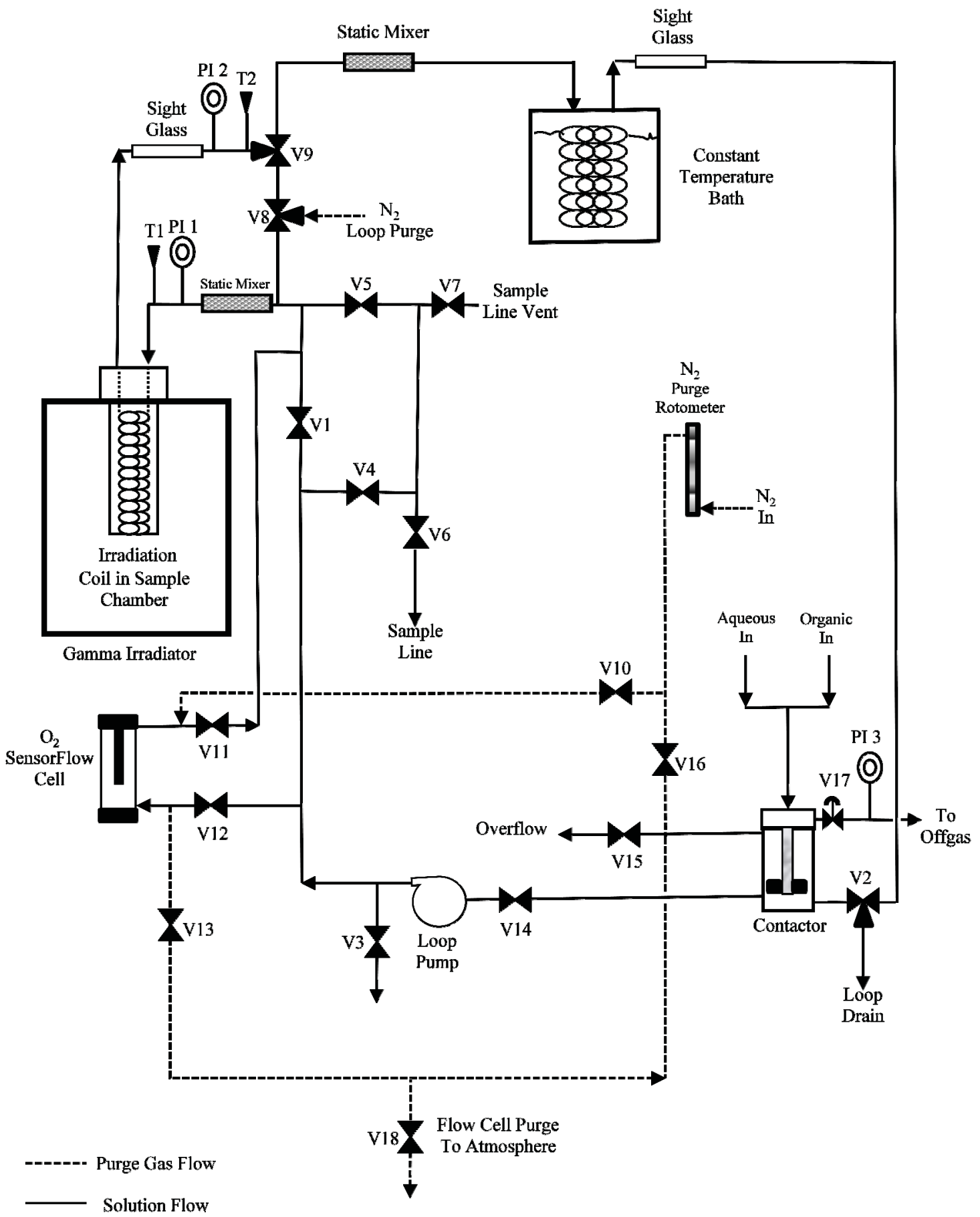

Figure 2. Schematic diagram of the INL Radiolysis and Hydrolysis Test Loop. 


\subsection{Solvent Extraction Experiments}

In order to gauge the effect of gamma radiolysis upon the extraction performance of the TRUEX solvent used in this study, americium distribution ratios were measured as a function of absorbed dose. All chemicals were reagent grade or higher (Sigma Aldrich). Radiotracers $\left({ }^{241} \mathrm{Am}\right)$ were obtained from laboratory stocks. Aqueous solutions were prepared using de-ionized water. All distribution ratio determinations were performed in triplicate unless otherwise noted.

A simplified flowsheet (not shown) was employed to evaluate the effect of gamma radiolysis on the strip section of the TRUEX process flowsheet. The concentration of radiotracers present in the organic and aqueous phases was determined by gamma spectrometry. The americium distribution ratio was calculated as the ratio of activity in the organic and aqueous phases, $\mathrm{D}=[\mathrm{M}] \mathrm{org} /[\mathrm{M}] \mathrm{aq}$. The organic to aqueous phase volume ratio $(\mathrm{O} / \mathrm{A})$ used for all contacts was $\mathrm{O} / \mathrm{A}=1.0$. The solvent extraction experiments were performed at ambient temperature $\left(21 \pm 2{ }^{\circ} \mathrm{C}\right)$.

\subsection{Ion Chromatographic Analysis}

A Dionex (Sunnyvale, CA, USA) ICS-5000 ion chromatograph equipped with an eluent generator, an autosampler, dual quaternary gradient pumps with degas, conductivity detector, and an anion selfregenerating suppressor (ASRS) was used for all IC experiments. All columns and other consumables were obtained from Dionex. An IonPac AG11-HC guard column (2mm x 50mm) and IonPac AS11-HC analytical column $(2 \mathrm{~mm} \times 250 \mathrm{~mm})$, a CR-ATC continuously regenerated anion trap column, and an ASRS 300 anion suppressor were used. The flow rate was $0.5 \mathrm{~mL} / \mathrm{min}$. The eluent generator used was an EluGen II KOH cartridge. Deionized (DI) water generated by a water purification system (Barnstead EPure, ThermoScientific) was used for the preparation of all eluents, standards, and samples. All analyses were performed in triplicate.

The gradient elution protocol used for the IC analyses is given in Table 1.

Table 1. Gradient elution protocol used for IC analysis.

\begin{tabular}{c|c} 
Time, min & {$\left[\mathrm{OH}^{-}\right], \mathrm{mM}$} \\
\hline $0.0-8.0$ & 1.0 \\
$8.0-20.0$ & 15.0 \\
$20.0-27.0$ & 80.0 \\
$27.0-45.0$ & 1.0
\end{tabular}

\subsection{Determination of solvent dispersion number}

The dimensionless number for characterizing dispersions for batch contacts is 


$$
N_{D i}=\frac{1}{t_{B}} \sqrt{\frac{\Delta Z}{g}}
$$

where $t_{B}$ is the time for the dispersion band to break, $\Delta \mathrm{Z}$ refers to the initial thickness of the dispersion band, and $g$ is the gravitational constant $\left(9.81 \mathrm{~m} / \mathrm{s}^{2}\right)$. [7] General $\mathrm{N}_{D i}$ ranges for stage solvent extraction equipment are as follows. An $\mathrm{N}_{\mathrm{Di}}$ of $2 \times 10^{-4}$ would be poor; $4 \times 10^{-4}$, fair; $8 \times 10^{-4}$, good; and $\geq$ $16 \times 10^{-4}$, excellent. Solvents with $\mathrm{N}_{\mathrm{Di}}$ values $<2 \times 10^{-4}$ would probably be unacceptable.

Batch contacts were performed and $\mathrm{N}_{\mathrm{Di}}$ values were established with TRUEX solvent and TRUEX aqueous strip solutions. Measurements for $\mathrm{N}_{\mathrm{Di}}$ calculations were taken multiple times at ambient laboratory temperature. Determinations were performed using a stoppered $150 \mathrm{~mL}$ graduated cylinder. Phase volumes were calculated from predetermined phase ratios and organic and aqueous solutions were added to the glass graduated cylinder by pipette. Column height in the graduated cylinder was recorded. Phases were mixed by holding the graduated cylinder by hand in a horizontal position perpendicular to the experimenters arm, and shaking the cylinder side to side at a rate of 1.5 to 2 cycles per second. Care was taken to shake each contact as consistently as possible. For each contact, cylinder contents were mixed 20 seconds, held 10 seconds in an upright position, and mixed 20 additional seconds. Immediately after the second mix interval, the cylinder was placed in an upright position and a stop watch was used to time phase disengagement of the coalescing dispersion band. This step was considered complete when the last droplet in the dispersion band broke. In contacts where complete disengagement wasn't achieved in a reasonable time, an estimated percent disengagement along with the time was recorded.

\subsection{Determination of Dissolved Oxygen}

The concentration of dissolved oxygen (DO) present in the test loop was determined using a DO probe (556 Multiparameter system, YSI, Inc., Yellow Springs, OH). The DO probe used a steady state polarographic sensor and a 1.0 mil Telfon membrane and electrolyte (YSI, Inc.). The sensor probe was installed in an YSI Model 3059 flow cell and coupled with an YSI 556 data logger. The flow cell (see Figure 2) was installed in parallel to the test loop flow path in order to allow operation of the test loop with or without installation of the DO probe.

\section{Results}

Experiments completed during FY-2012 focused upon examination of the affect of gamma radiolysis upon the stripping section of the TRUEX flowsheet. The TRUEX stripping solution is comprised of a mixture of lactic acid and diethylenetriaminepentaacetic acid (DTPA). Static irradiations of the TRUEX strip solution alone and in contact with TRUEX solvent were performed using the ${ }^{60} \mathrm{Co}-\gamma$-irradiation from the Nordion GammaCell 200E (Ottawa, Canada) irradiator. The TRUEX strip solution was also irradiated in contact with TRUEX using the INL test loop and the Nordion GammaCell 200E (Ottawa, Canada) irradiator. The current irradiator sample chamber center-line dose rate is $6.4 \mathrm{kGy} / \mathrm{hr}$. The effective absorbed gamma dose rate of $3.3 \mathrm{kGy} / \mathrm{hr}$ delivered to samples in the test loop was based upon decay-corrected Fricke dosimetry, [8] the photo-bleaching of a methyl red solution due to gamma irradiation, [9] and the duration of each irradiation. 


\subsection{Solvent Extraction Experiments}

All batch contacts were performed in triplicate using an organic to aqueous phase volume ratio $(\mathrm{O} / \mathrm{A})$ of 1.0. The contacts were vortex mixed for 2 minutes and centrifuged for 2 minutes at 2000 revolutions per minute (RPM). All aqueous, organic and feed samples were $0.5 \mathrm{ml}$ volumes. All contacts were performed at ambient temperature $\left(21 \pm 2{ }^{\circ} \mathrm{C}\right)$.

\subsubsection{Static Irradiation of TRUEX Strip Stage}

The initial experiments performed to investigate the affect of gamma radiolysis upon the stripping section of a TRUEX flowsheet involved static irradiations of the TRUEX stripping solution alone and in contact with an equal volume of TRUEX solvent. These irradiations were conducted in capped glass scintillation vials.

The americium distribution ratios determined for irradiated TRUEX strip solution alone (open circles, Figure 3) and irradiated strip solution in contact with TRUEX solvent (open squares, Figure 3) are plotted as function of absorbed dose in Figure 3. No statistically significant variation in the measured americium distribution ratios is observed. Due to the low magnitude of these distribution ratios it is difficult to conclude that the lack of a clear dependence upon absorbed dose is due to the uncertainty in the data set or to the absence of an effect due to the production of radiolytic degradation products.

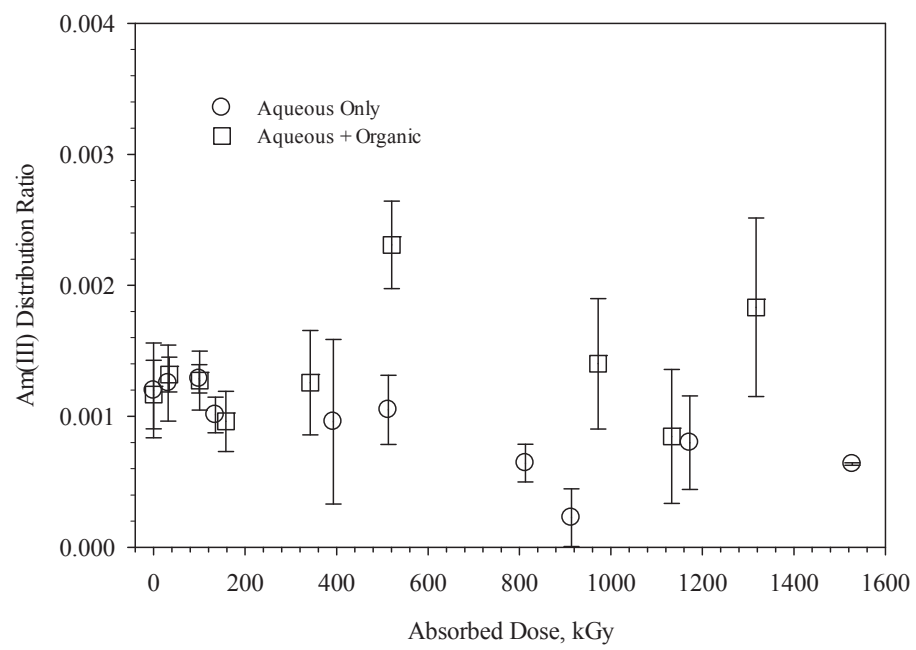

Figure 3. Am(III) distribution ratios as a function of absorbed dose for static irradiation of the TRUEX aqueous strip only (open circles) and static irradiation of TRUEX strip phase in contact with TRUEX sovlent (open squares).

\subsubsection{Test Loop Irradiation of TRUEX Strip Stage}

In order to further elucidate any potential effects of gamma radiolysis upon the stripping section of a TRUEX flowsheet, the TRUEX stripping solution was irradiated in the INL radiolysis test loop while in contact with TRUEX solvent. These irradiations were conducted with the test loop operating under an ambient atmosphere, i.e. all solutions were exposed to atmospheric oxygen. 
The americium distribution ratios determined for irradiated TRUEX strip solution plus irradiated TRUEX solvent (open circles, Figure 4) and irradiated TRUEX strip solution plus fresh TRUEX solvent (open squares, Figure 4) are plotted as function of absorbed dose in Figure 4. Interestingly, a statistically significant variation in the americium stripping distribution ratio as a function of absorbed dose is observed for the fully irradiated solvent system. No statistically significant variation in the determined americium stripping distribution ratios is observed in the case of irradiated strip solution and fresh TRUEX solvent. This result indicates that the radiolytic processes in the TRUEX strip section lead to the formation of organic soluble degradation products.

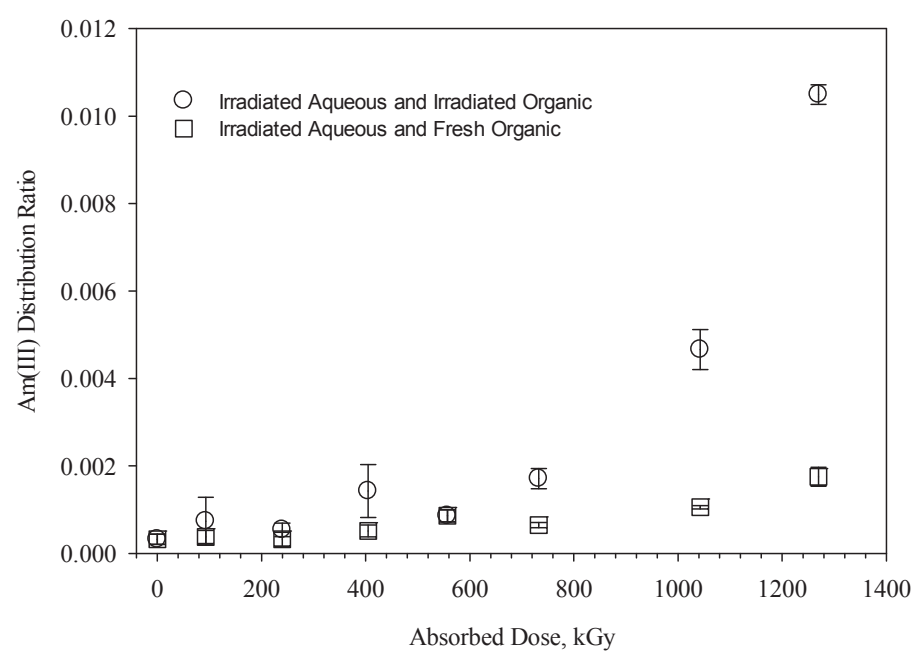

Figure 4. Am(III) distribution ratios as a function of absorbed dose for test loop irradiation of the TRUEX aqueous strip in contact with TRUEX solvent. Determination with irradiated aqueous and organic phases (open circles) and irradiated aqueous and fresh organic (open squares).

\subsection{Ion Chromatography Analysis}

\subsubsection{Static Irradiation of TRUEX Strip Stage}

The concentration of lactic acid in samples of TRUEX strip solution subjected to static gamma irradiation was determined by ion chromatography. Attempts to determine the concentration of DTPA present in these samples by IC analysis were not successful. A typical calibration curve for the IC determination of lactic acid is shown in Figure 5. The response is linear over at least two orders of magnitude in lactic acid concentration and the magnitude of the standard deviation of the mean $(1 \sigma)$ is smaller than the data markers used in Figure 5. 


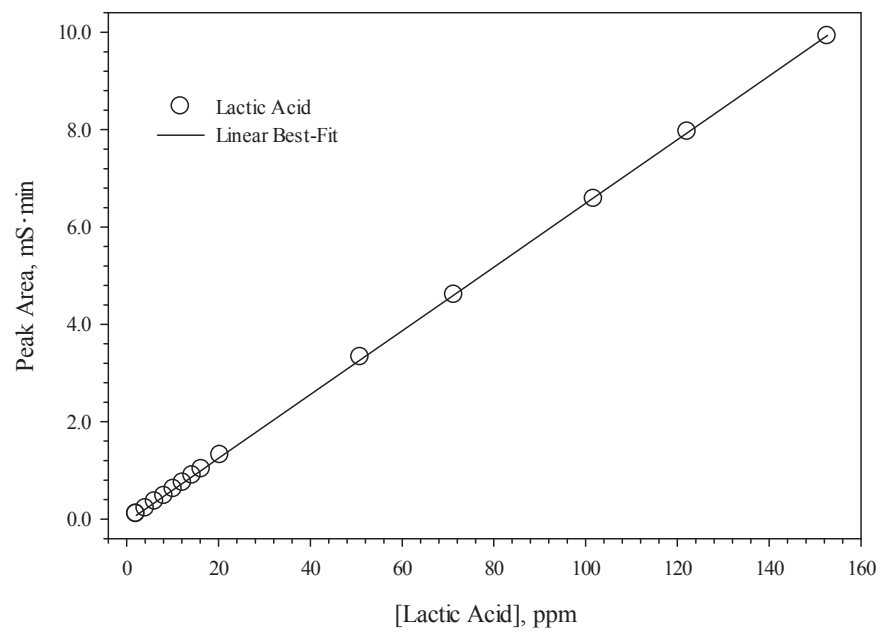

Figure 5. Plot of peak area response versus lactic acid concentration for the ion chromatographic determination of lactic acid in solution.

The the analytical concentration of lactic acid determined by IC analysis for the static irradiation of the TRUEX strip solution only is shown in Figure 6. This plot shows a significant loss of lactic acid as the TRUEX strip solution is subjected to gamma irradiation. Several additional new peaks were observed in the IC chromatograms as a function of increasing absorbed dose. These degradation products were not quantified.

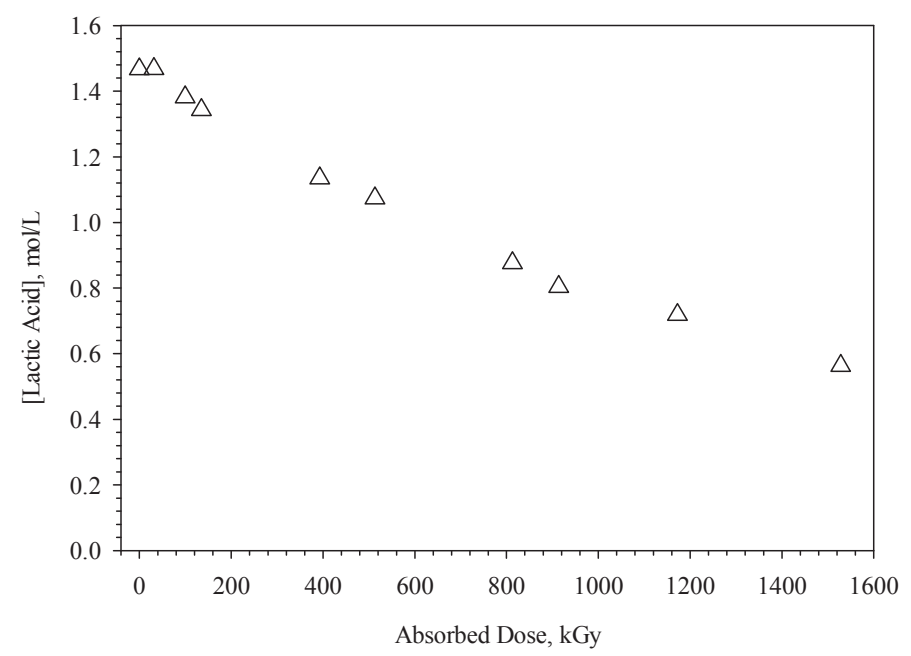

Figure 6. Plot of the concentration of lactic acid determined by ion chromatography as a function of absorbed dose for the static irradiation of TRUEX strip phase only. 


\subsection{Solvent Dispersion Number}

An interesting observation regarding the speed of aqueous and organic phase disengagement of the un-irradiated and irradiated TRUEX stripping section was made. As shown in Figures $7-10$, the time required for complete phase disengagement increases dramatically. At an absorbed dose of $240 \mathrm{kGy}$, greater than four minutes is required for phase separation (see Figure 7). However, at an absorbed dose of $1040 \mathrm{kGy}$ greater than eight minutes is required for phase separation (see Figure 9).

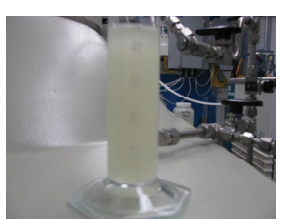

$\mathrm{T}=0 \mathrm{~min}$

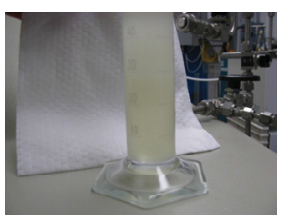

$\mathrm{T}=2 \mathrm{~min}$

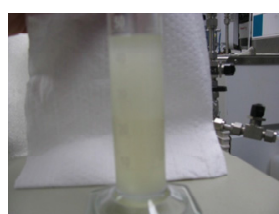

$\mathrm{T}=3 \mathrm{~min}$

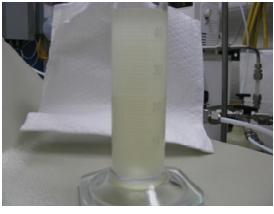

$\mathrm{T}=4 \mathrm{~min}$

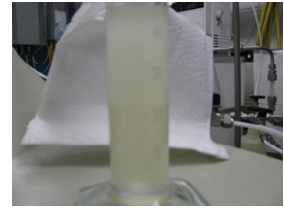

$\mathrm{T}=5 \mathrm{~min}$

Figure 7. Phase separation of irradiated TRUEX solvent and TRUEX strip solution after $240 \mathrm{kGy}$ absorbed dose. Complete phase separation requires greater than four minutes.

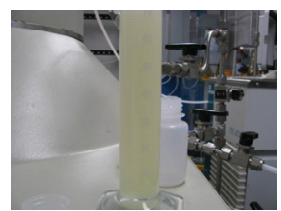

$\mathrm{T}=0 \mathrm{~min}$

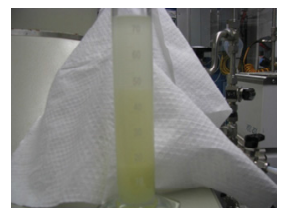

$\mathrm{T}=3 \mathrm{~min}$

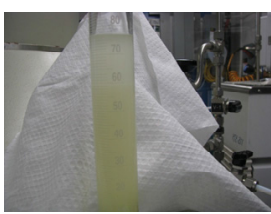

$\mathrm{T}=1 \mathrm{~min}$

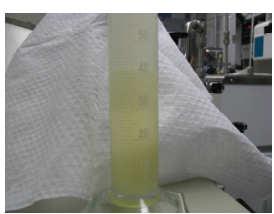

$\mathrm{T}=4 \mathrm{~min}$

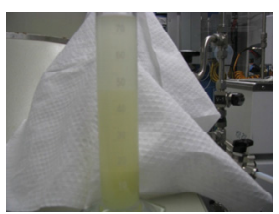

$\mathrm{T}=2 \min$

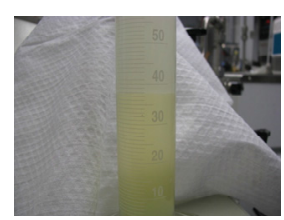

$\mathrm{T}=5 \mathrm{~min}$

Figure 8. Phase separation of irradiated TRUEX solvent and TRUEX strip solution after $400 \mathrm{kGy}$ absorbed dose. Complete phase separation requires greater than four minutes. 


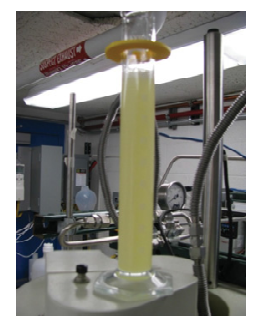

$\mathrm{T}=0 \mathrm{~min}$

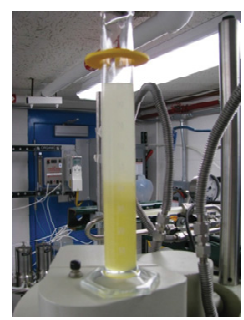

$\mathrm{T}=6 \mathrm{~min}$

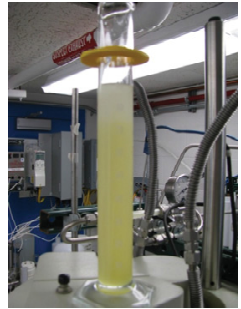

$\mathrm{T}=2 \mathrm{~min}$

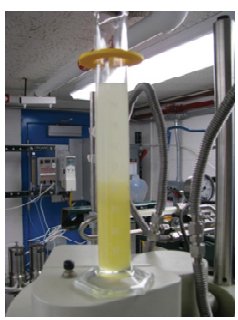

$\mathrm{T}=8 \mathrm{~min}$

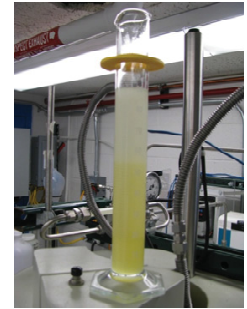

$\mathrm{T}=4 \mathrm{~min}$

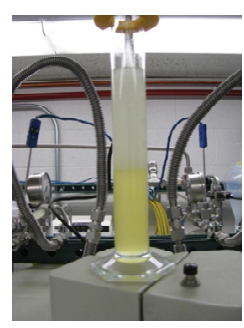

$\mathrm{T}=23 \mathrm{~min}$

Figure 9. Phase separation of irradiated TRUEX solvent and TRUEX strip solution after $1040 \mathrm{kGy}$ absorbed dose. Complete phase separation requires greater than eight minutes.

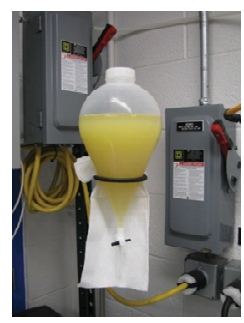

$\mathrm{T}=0 \mathrm{~min}$

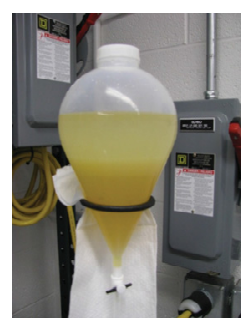

$\mathrm{T}=4 \mathrm{~min}$

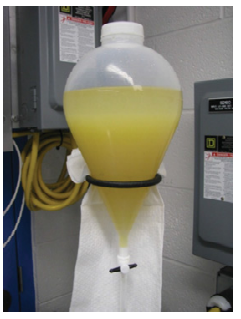

$\mathrm{T}=1 \mathrm{~min}$

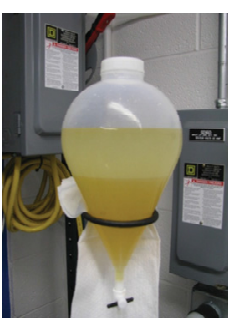

$\mathrm{T}=6 \mathrm{~min}$

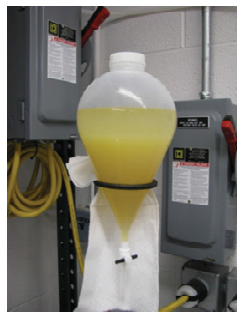

$\mathrm{T}=3 \mathrm{~min}$

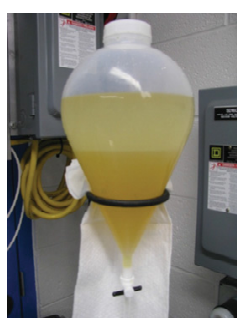

$\mathrm{T}=10 \mathrm{~min}$

Figure 10. Phase separation of irradiated TRUEX solvent and TRUEX strip solution after $1270 \mathrm{kGy}$ absorbed dose. Complete phase separation requires greater than six minutes. 
TRUEX Radiolysis Testing Using the INL Radiolysis Test Loop: FY-2012 Status Report

September 28, 2012

In order further investigate this variation in the time required for complete phase disengagement, dispersion numbers were determined for the following TRUEX solvent systems:

1.) un-irradiated organic solvent and un-irradiated strip solution

2.) irradiated organic solvent and irradiated strip solution (1270 kGy absorbed dose)

3.) un-irradiated organic solvent and irradiated strip solution

4.) irradiated organic solvent and un-irradiated strip solution.

Due to limitations in the available volume of test loop sample taken during the radiolysis experiment, it was not possible to determine values of the dispersion number as a function of absorbed dose. The details of these determinations and the dispersion number for the differing solution conditions are listed in Table 2. An $\mathrm{N}_{\mathrm{Di}}$ of $2 \times 10^{-4}$ would be poor; $4 \times 10^{-4}$, fair; $8 \times 10^{-4}$, good; and $\geq 16 \times 10^{-4}$, excellent. Solvents with $\mathrm{N}_{\mathrm{Di}}$ values $<4 \times 10^{-4}$ would probably be unacceptable. The dispersion numbers presented in Table 2 are excellent for the un-irradiated materials but show likely unacceptable values for the irradiated solutions.

Table 2. Break times, temperatures, and values of $\mathrm{N}_{\mathrm{Di}}$ for the investigated solvent systems.

\begin{tabular}{|c|c|c|c|c|}
\hline $\begin{array}{l}\text { Break } \\
\text { time, s }\end{array}$ & $\begin{array}{l}\text { Temperature } \\
\text { before mixing, } \\
{ }^{\circ} \mathrm{C}\end{array}$ & $\begin{array}{r}\text { Temperature } \\
\text { after mixing, }{ }^{\circ} \mathrm{C}\end{array}$ & $\mathrm{N}_{\mathrm{Di}}$ & Average $\mathrm{N}_{\mathrm{Di}}$ \\
\hline \multicolumn{5}{|c|}{ un-irradiated organic solvent and un-irradiated strip solution } \\
\hline 92 & 19.5 & 19.9 & $1.07 \times 10^{-3}$ & \multirow{3}{*}{$1.05 \times 10^{-3} \pm 1.72 \times 10^{-5}$} \\
\hline 93 & 20.1 & 20.5 & $1.06 \times 10^{-3}$ & \\
\hline 95 & 20.5 & 20.2 & $1.04 \times 10^{-3}$ & \\
\hline \multicolumn{5}{|c|}{ irradiated organic solvent and irradiated strip solution } \\
\hline 249 & 19.6 & 20.5 & $3.95 \times 10^{-4}$ & \multirow{3}{*}{$3.94 \times 10^{-4} \pm 1.57 \times 10^{-6}$} \\
\hline 251 & 20.5 & 20.5 & $3.92 \times 10^{-4}$ & \\
\hline 250 & 20.5 & 20.7 & $3.94 \times 10^{-4}$ & \\
\hline \multicolumn{5}{|c|}{ un-irradiated organic solvent and irradiation strip solution } \\
\hline 173 & 19.3 & 20.2 & $5.69 \times 10^{-4}$ & \multirow{3}{*}{$5.80 \times 10^{-4} \pm 1.44 \times 10^{-5}$} \\
\hline 165 & 20.2 & 20.8 & $5.97 \times 10^{-4}$ & \\
\hline 171 & 20.8 & 20.9 & $5.76 \times 10^{-4}$ & \\
\hline \multicolumn{5}{|c|}{ Irradiated organic solvent and un-irradiated strip solution } \\
\hline 203 & 20.3 & 20.9 & $4.85 \times 10^{-4}$ & \multirow{3}{*}{$4.85 \times 10^{-4} \pm 4.78 \times 10^{-6}$} \\
\hline 205 & 20.9 & 21.5 & $4.80 \times 10^{-4}$ & \\
\hline 201 & 21.5 & 21.9 & $4.90 \times 10^{-4}$ & \\
\hline
\end{tabular}




\subsection{Dissolved Oxygen}

The INL is evaluating the impacts of gamma radiolysis and hydrolysis on the efficacy of solvent extraction process solvents. These effects are investigated by irradiating neat organic solutions or mixtures of aqueous and organic solutions under static conditions in the INL gamma irradiator. The INL test loop system is used to irradiate mixtures of aqueous and organic phases under flowing conditions. Results of testing under these varied conditions indicate that, in general, the greatest extent of radiolytic damage occurs during the static irradiation of neat organic samples and the least radiolytic damage occurs during irradiation in the test loop. The lesser degradation observed in the test loop irradiations is attributed to the presence of dissolved oxygen in the solutions irradiated in the test loop. Dissolved oxygen reacts very rapidly with many radical species and may serve as a radical scavenger during radiolysis.

In order to determine the importance of oxygen in radiolytic degradation of process solvents, the test loop apparatus was, recently, modified to include a dissolved oxygen (DO) probe and an oxidation reduction probe (ORP). Preliminary experiments have demonstrated the complete consumption of dissolved oxygen when irradiating either water or sodium nitrate solutions in the sealed test loop. These solutions were chosen for initial testing due to concerns of the mechanical and chemical stability of the dissolved oxygen probe. When irradiating water or sodium nitrate in the test loop under an ambient atmosphere, the amount of dissolved oxygen decreases by approximately $15 \%$ after receiving approximately $50 \mathrm{kGy}$ absorbed dose. Initial experiments in which a mixture of nitric acid and $\mathrm{TBP} / \mathrm{n}$ dodecane were irradiated under an ambient atmosphere demonstrated that the amount of dissolved oxygen present in the solution remained relatively constant during the period of the irradiation. However, the polyethylene semi-permeable membrane used in the dissolved oxygen monitor during the mixed phase irradiation was not reliable. The repeated failure of the polyethylene membrane prevented accurate determination of the dissolved oxygen present in the test loop. In addition, the significantly lower solubility of oxygen in an aliphatic organic, relative to its solubility in water, further complicates the determination of concentration of dissolved oxygen in the biphasic system.

\section{Discussion}

Previously, the INL radiolysis and hydrolysis test loop has been used to evaluate the effects of hydrolytic and radiolytic degradation upon the efficacy of the extraction section of a TRUEX flowsheet used for the recovery of trivalent actinides and lanthanides from acidic solution. $[10,11]$ The nominal composition of the TRUEX solvent used in this study is 0.2 M CMPO and 1.4 M TBP dissolved in ndodecane. The results demonstrate that solvent hydrolysis does not adversely impact the performance of the process flowsheet. However, hydrolysis does likely account for the small amount of HDBP present in the un-irradiated solvent. Gamma irradiation of a mixture of TRUEX process solvent and nitric acid in the test loop does adversely impact flowsheet performance as measured by the decreasing americium and europium distribution ratios in the extraction section as accumulated dose increases. The radiolytic degradation products, which are, in part, responsible for the decrease in extraction distribution ratios, inhibit stripping of the irradiated TRUEX solvent with dilute nitric acid. Use of an aqueous complexant, i.e. DTPA, in the aqueous strip solution easily overcomes the decreased stripping performance.

The efficiency of the conversion of absorbed radiation energy (gamma rays) into chemical products is defined here as the $G$-value, in units of $\mu \mathrm{mol} \cdot \mathrm{L}^{-1} \cdot \mathrm{Gy}^{-1}$. A $G$-value can be used to predict the extent of radiolytic degradation of a solvent component for a given absorbed dose. The americium stripping distribution ratios (see Figure 4, open circles) determined for TRUEX solvent and stripping solution irradiated in the test loop increased with increasing absorbed dose. This increase in the magnitude of the 
stripping distribution may be attributed to either the formation of organic soluble compounds which inhibit stripping or to the consumption of the TRUEX stripping reagent due to radiolytic degradation. This information is useful for the prediction of the over-all performance of a TRUEX flowsheet in a radiation field. To this end, the concentration of lactic acid present in TRUEX solution irradiated in the absence of an organic phase was used to calculate a $G$-value for lactic acid radiolytic degradation. The slope of the linear best-fit to a plot of lactic acid concentration versus absorbed dose corresponds to the $G$ value for the radiolytic decomposition of lactic acid. The determined $G$-value for the destruction of lactic acid is $-G_{\mathrm{LA}}=-0.617 \pm 0.033 \mu \mathrm{mol} \cdot \mathrm{L}^{-1} \cdot \mathrm{Gy}^{-1}$.

Unfortunately, the samples of TRUEX solvent and stripping solution subjected to static irradiation in contact with each other and the samples from the test loop irradiation have not yet been analyzed. Therefore, it is not possible to attribute the increase in Am stripping distribution ratio as a function of absorbed dose observed for the test loop irradiation to a simple decrease in the available lactic acid present in the strip solution.

Groenewold et al. [12] have used electrospray ionization mass spectrometry (ESI-MS), to identify degradation products produced during the gamma irradiation of CMPO dissolved in dodecane. These researchers identified octylphenylphosphinic acid and phenyl-N,N-diisobutylcarbamoylmethyl phosphine oxide in the irradiated CMPO solutions. Similar radiolytic degradation products have been suggested by other researchers studying the potential impacts of radiolysis on TRUEX flowsheets utilizing a tetrachloro-ethylene [13] or dodecane [14] diluents. While these degradation species have not been identified in the TRUEX solutions irradiated in the INL test loop, it is reasonable to assume similar degradation processes occur in both experiments. The consumption of CMPO during radiolysis to form degradation products such as those identified by Groenewold et al., readily explains the decrease in extraction distribution ratios observed in for TRUEX solvent irradiated during FY-2011 and FY-2012. [15] However, recent experiments have focused upon developing a detailed understanding of the impacts of gamma radiolysis upon the stripping section of a TRUEX flowsheet. An increase in the stripping americium distribution ratios with increasing dose was observed (see Figure 4, open circles) when TRUEX solvent was irradiated in contact with the TRUEX stripping solution in the test loop. This suggests that the radiolytic degradation products formed during irradiation of TRUEX solvent in contact with the TRUEX strip solution (1.5 M lactic acid, $0.05 \mathrm{M}$ DTPA, $\mathrm{pH} \sim 5$ ) may differ from the products formed during irradiation of TRUEX solvent in contact with $4.4 \mathrm{M} \mathrm{HNO}_{3}$.

In the presence of dissolved oxygen and nitric acid, the strongly reducing solvated electron, $\mathrm{e}_{\mathrm{aq}}^{-}$, (produced via direct radiolysis of water) is rapidly converted to other species according to the following equations [16]

$$
\begin{gathered}
\mathrm{e}_{\mathrm{aq}}^{-}+\mathrm{H}^{+} \rightarrow \mathrm{H}^{\bullet} \quad k=2.3 \times 10^{10} \mathrm{Lmol}^{-1} \mathrm{~s}^{-1} \\
\mathrm{e}_{\mathrm{aq}}^{-}+\mathrm{O}_{2} \rightarrow \mathrm{O}_{2}^{-} \quad k=1.9 \times 10^{10} \mathrm{Lmol}^{-1} \mathrm{~s}^{-1} \\
\mathrm{e}_{\mathrm{aq}}^{-}+\mathrm{NO}_{3}^{-} \rightarrow \mathrm{NO}_{3}^{-2} \bullet \quad k=9.7 \times 10^{9} \mathrm{Lmol}^{-1} \mathrm{~s}^{-1}
\end{gathered}
$$

The $\mathrm{H}^{\bullet}$ radical is also rapidly converted to the hydroperoxy radical, $\mathrm{HO}_{2}^{\bullet}$, in the presence of oxygen according to:

$$
\mathrm{H}^{\bullet}+\mathrm{O}_{2} \rightarrow \mathrm{HO}_{2}^{\bullet} k=2.1 \times 10^{10} \mathrm{Lmol}^{-1} \mathrm{~s}^{-1}
$$

and the superoxide radical, ${ }^{\bullet} \mathrm{O}_{2}^{-}$, may be protonated to form 


$$
\mathrm{H}^{+}+{ }^{\bullet} \mathrm{O}_{2}^{-} \Leftrightarrow \mathrm{HO}_{2}^{\bullet} \quad \mathrm{p} K_{a}=4.8
$$

Both the superoxide radical anion and hydroperoxy radical lead to the formation of $\mathrm{H}_{2} \mathrm{O}_{2}$ as demonstrated by the following reactions:

$$
\begin{aligned}
& 2 \mathrm{HO}_{2}^{\bullet} \rightarrow \mathrm{H}_{2} \mathrm{O}_{2} \quad k=7.6 \times 10^{5} \mathrm{Lmol}^{-1} \mathrm{~s}^{-1} \\
& \cdot \mathrm{O}_{2}^{-}+\mathrm{HO}_{2}^{\bullet}+\mathrm{H}_{2} \mathrm{O} \rightarrow \mathrm{H}_{2} \mathrm{O}_{2}+\mathrm{O}_{2}+\mathrm{OH}^{-} \quad k=8.5 \times 10^{7} \mathrm{Lmol}^{-1} \mathrm{~s}^{-1} .
\end{aligned}
$$

However, in strongly acidic solution the hydroperoxy radical can be protonated to form:

$$
\mathrm{HO}_{2}^{\bullet}+\mathrm{H}^{+} \rightarrow{ }^{\bullet} \mathrm{H}_{2} \mathrm{O}_{2}^{+} \quad \mathrm{p} K_{\mathrm{a}} \sim 1.2 .
$$

Therefore, the presence of dissolved oxygen in the test loop during irradiation may serve to convert highly reactive radical species into molecular species, i.e. $\mathrm{H}_{2} \mathrm{O}_{2}$, which exhibit less reactivity. The protonation of the hydroperoxy radical to form the hydrogen peroxide radical cation may, also, explain the differences observed in the stripping distributions when using TRUEX solvent irradiated in contact with high concentrations of nitric acid or the lactic acid/DTPA stripping solution.

The over-all importance of dissolved oxygen for the generation of radiolytic degradation is still unclear. In the coming fiscal year, test irradiations under an inert atmosphere will be performed. It is anticipated that the results of irradiation under an inert atmosphere and more accurate measurement of the dissolved oxygen content present during ambient atmosphere irradiations will enable a more definitive explanation the role dissolved oxygen plays in the radiolytic degradation of solvent extraction process solvents. However, the preceding equations may serve to demonstrate how a change in the composition of the aqueous phase in contact with the TRUEX solvent during gamma irradiation leads to the formation of differing reactive molecular species in the extraction and stripping sections of the flowsheet. The reactive molecular species formed during irradiation of the extraction section of the TRUEX flowsheet (4.4 $\mathrm{M} \mathrm{HNO}_{3}$ ) may likely be different than those formed during irradiation of the strip section of the same flowsheet $\left(\sim 1 \times 10^{-5} \mathrm{M} \mathrm{HNO}_{3}\right)$. Consequently, the suite of the degradation products formed from the irradiation of different sections of the TRUEX flowsheet may have differing impacts upon the efficiency of stripping.

While the observed increases in the americium stripping distributions with increasing absorbed dose are statistically significant, the increase from $\mathrm{D}_{\mathrm{Am}}=<0.001$ at $0 \mathrm{kGy}$ absorbed dose to $\mathrm{D}_{\mathrm{Am}}=0.015$ at $1300 \mathrm{kGy}$ absorbed dose is not an insurmountable difficulty. A more troubling observation is the significant decrease in the solvent dispersion number as the strip section of the TRUEX flowsheet is subjected to gamma radiolysis. The dispersion number, $\mathrm{N}_{\mathrm{Di}}$, determined for un-irradiated TRUEX solvent and strip solution is $\mathrm{N}_{\mathrm{Di}}=1.05 \times 10^{-3}$, which is an acceptable value for typical solvent extraction equipment. However, the dispersion number for the irradiated TRUEX solvent and strip solution is 3.94 $\mathrm{x} 10^{-4}$, which is a poor value for typical solvent extraction equipment. Dispersion number determinations for mixture of irradiated and un-irradiated solutions (see Table 2) suggest that both the aqueous and organic phases play a role in the decrease in the solvent dispersion number. The depiction of the time required for phase disengagement shown in Figures $8-11$, suggest that the decrease in dispersion number values may become important at relatively low values of absorbed dose. Therefore, it is necessary to determine values of $\mathrm{N}_{\mathrm{Di}}$ as a function of absorbed dose for the various sections of the TRUEX flowsheet. 


\section{Conclusions and Continuing Investigations}

The INL test loop has been used to evaluate the effects of gamma radiolysis upon the efficacy of the strip section of a TRUEX flowsheet for the recovery of trivalent actinides and lanthanides from acidic solution. The nominal composition of the TRUEX strip solution used in this study is $1.5 \mathrm{M}$ lactic acid and $0.05 \mathrm{M}$ DTPA dissolved in water. The nominal composition of the TRUEX solvent used in this study is $0.2 \mathrm{M} \mathrm{CMPO}$ and 1.4 M TBP dissolved in n-dodecane. Gamma irradiation of a mixture of TRUEX process solvent and strip solution in the test loop does result in statistically significant increase in the measured americium stripping distribution ratios. However, this increase in $\mathrm{D}_{\mathrm{Am}}$ for solvent stripping would likely have little impact upon the efficacy of the TRUEX process flowsheet. The values of the solvent dispersion number determined for the un-irradiated and irradiated TRUEX strip section indicate that slow phase disengagement may present a challenge to the implementation of the TRUEX flowsheet.

Continuing work will initially focus upon the completion of the analysis of samples generated during FY-12. The results of these analyses will be used to calculate $G$-values for the destruction of lactic acid and DTPA due to gamma radiolysis. In addition, attempts will be made to identify differences, if any, in the suite of radiolytic degradation products formed during the irradiation of the extraction and strip sections of the TRUEX flowsheet. The importance of dissolved oxygen in terms of the production of radiolytic degradation products will be investigated by performing irradiations under ambient and inert environments. In addition, experiments will be conducted in order to attempt to quantify the concentration of dissolved oxygen present in the test loop under the various irradiation conditions used. In order to determine how gamma radiolysis may impact the hydrodynamic behavior of the strip section of the TRUEX flowsheet, the variation in the value of the solvent dispersion number will be measured as a function of absorbed dose. If necessary, the solvent dispersion numbers will be determined for the extraction section of the TRUEX flowsheet. 
TRUEX Radiolysis Testing Using the INL Radiolysis Test Loop: FY-2012 Status Report

\section{Acknowledgements}

The authors thank Bruce J. Mincher for the many useful discussions of radiation chemistry in aqueous and organic solutions. 


\section{References}

1. Mincher, B. J.; Modolo, G.; Mezyk, S. P. "The effects of radiation chemistry on solvent extraction: 1. conditions in acidic solution and a review of TBP radiolysis," Solvent Extr. Ion Exch. 2009, 27, 1 - 25.

2. Mincher, B. J.; Modolo, G.; Mezyk, S. P. "The effects of radiation chemistry on solvent extraction: 3. A review of actinide and lanthanide extraction," Solvent Extr. Ion Exch. 2009, 27, 579 - 606.

3. Buxton, G. V.; Greenstock, C. L.; Helman, W. P.; Ross, A. B. "Critical Review of rate constants for reactions of hydrated electrons, hydrogen atoms and hydroxyl radicals in aqueous solution," J. Phys. Chem. Ref. Data 1988, $17,513-866$.

4. Mincher, B. J.; Mezyk, S. P. "Radiation chemical effects on radiochemistry: A review of examples important to nuclear power," Radiochim. Acta 2009, 97, 519 - 534.

5. Mincher, B. J. An overview of selected radiation chemical reactions affecting fuel cycle solvent extraction. Ch. 15 in: Nuclear Energy and the Environment, ACS Symposium Series 1046, Wai, C. M.; Mincher, B. J., Eds. 2010.

6. Peterman, D. R.; Garn, T. G.; Herbst, R. Scott; Law, J. D.; Meikrantz, D. H.; Tillotson, R. D. "Completion of Design and Installation of Radiolysis/Hydrolysis Test Loop", Idaho National Laboratory, AFCI-SEPA-PMOMI-DV-2009-000122, July 23, 2009.

7. Leonard, R. A. "Solvent characterization using the dispersion number," Sep. Sci. Tech. 1955, 30, 1103 - 1122.

8. Sehested, H. The Fricke Dosimeter, in Manual on Radiation Dosimetry, Marcel Dekker, Inc. Holm, N. W.; Berry, R. J., Eds. 1970, $313-317$.

9. Ajji, Z. "Usability of aqueous solutions of methyl red as high-dose dosimeter for gamma radiation," Rad. Measure. 2006, 41, 438 - 442.

10. Peterman, D. R.; Mincher, B. J.; Elias, G.; Tillotson, R. D.; Riddle, C. L. "FY-2010 Status Report for the Radiolysis and Hydrolysis Test Loop," Idaho National Laboratory, FCR\&D-SEPA-2010-000185, September $29,2010$.

11. Peterman, D. R.; McDowell, R. G.; Olson, L. G.; Tillotson, R. D. "FY-2011 Status Report for the Radiolysis and Hydrolysis Test Loop,” Idaho National Laboratory, FCRD-SWF-2011-000286, September 9, 2011.

12. Groenewold, G. S.; Elias, G.; Mincher, B. J.; Mezyk, S. P.; LaVerne, J. A. "Characterization of CMPO and its radiolysis products by direct infusion ESI-MS,” Talanta 2012, 99, 909 - 917.

13. Nash, K. L.; Gatrone, R. C.; Clark, G. A.; Rickert, P. G.; Horwitz, E. P. "Hydrolytic and Radiolytic Degradation of O $\phi D(i B) C M P O:$ Continuing Studies," Sep. Sci. Tech. 1988, 23, 1355 - 1372.

14. Nash, K. L.; Rickert, P. G.; Horwitz, E. P. “Degradation of TRUEX-Dodecane Process Solvent," Solvent Extr. Ion Exch. 1989, 7, 655 - 675.

15. Peterman, D. R.; Olson, L. G.; McDowell, R. G.; Elias, G.; Law, J. D. "Summary of TRUEX Radiolysis Testing Using the INL Radiolysis Test Loop,” Idaho National Laboratory, FCRD-SWF-2012-000082.

16. Mincher, B. J. and Mezyk, S. P. "Radiation chemical effects on radiochemistry: A review of examples important to nuclear power," Radiochim. Acta 2009, 97, 519-524, and references therein. 